\title{
Risk Assessment of Reclaimed Water Utilization in Basin Based on GIS
}

\author{
Yanxia Zheng ${ }^{1,2,3}$, Shaoyuan Feng ${ }^{3}, \mathrm{Na} \mathrm{Jiang}^{3}$, and Qingyi Meng ${ }^{4}$ \\ ${ }^{1}$ College of Resources and Environmental Sciences, China Agricultural University, \\ Beijing 100083, P. R. China \\ ${ }^{2}$ Institute of Resources and Environmental Sciences, Shijiazhuang University, \\ Hebei 050035, P. R. China \\ ${ }^{3}$ Center for Agricultural Water Research in China, China Agricultural University, \\ Beijing 100083, P. R. China \\ ${ }^{4}$ Beijing Hydraulic Research Institute, Beijing 100044, P. R. China \\ youth_zyx@126.com
}

\begin{abstract}
The reclaimed utilization of urban wastewater is an indispensable way for solving the crisis of urban water resource. In order to meet the needs of reclaimed water pollution control, the risk assessment model for reclaimed water utilization in basin are established. GIS was employed to derive all the data and evaluate model in order to get spatial variance and distribution of the risk levels on different scales within study area. The evaluation results can supply the pollution control with target areas. Based on the analysis of reclaimed water data of Beiyun river basin, the paper sets up an index system of risk assessment of reclaimed water. In addition, it applies the mathematics theory to making a comprehensive assessment on the utilizing risk of reclaimed water in the research object, which provides a scientific foundation for risk management of reclaimed water in theory and practice.
\end{abstract}

Keywords: Reclaimed water, Risk assessment, GIS, Beiyun river.

\section{Introduction}

There is an increasing trend to require more efficient use of water resources, both in urban and rural environments. Wastewater reclamation has been the subject of a number of studies. Types of wastewaters used for recycling include treated and untreated sewage effluent ${ }^{[1-3]}$, storm water runoff ${ }^{[2,4]}$, domestic greywater ${ }^{[5]}$, and industrial wastewater ${ }^{[2,6]}$. During the last decade, municipal wastewater reuse has emerged as an important means of supplementing water supplies in a large number of regions throughout the world. In many instances, reuse is also promoted as a means of limiting wastewater discharges to water environments. Wastewater reclamation is used in many ways. Effluents are reused for irrigation purposes in many countries around the world on all of the populated continents. Wastewaters can often contain significant concentrations of organic and inorganic nutrients for example nitrogen and phosphate. There is potential for these nutrients present in recycled water to be used as a fertilizer source when the water is recycled as an irrigation source for 
agriculture $^{[7,8]}$. There have been a number of risk factors identified for using reused waters for purposes such as agricultural irrigation. Some risk factors are short term and vary in severity depending on the potential for human, animal or environmental contact, while others have longer term impacts which increase with continued use of recycled water. So health and environmental risks associated with water reuse have been addressed.

The application of risk assessment to protect human health has grown over the last 60 years, but it is only during the last years that reclaimed water risk assessment has become more researched. The aim of reclaimed water risk assessment is the estimation of risk of adverse effects to communities of species in locations that are potentially exposed to pollutants.

Health and environmental risks associated with water reuse are now dealt with in a thorough manner by guidelines used in many countries. Guidelines pertaining to chemical contaminants are typically limited to bulk parameters such as chemical oxygen demand (COD), biochemical oxygen demand (BOD), $\mathrm{pH}$ and total suspended solids (TSS). In many situations these simple parameters provide suitable surrogate indications of the likely presence of chemical species of concern. However, for more highly treated reuse waters, they are of limited sensitivity. Furthermore, for some applications, an accurate assurance of specific chemical concentrations is important.

Today, the assessment of whether a substance can pose a potential risk to the organisms present in the environment is based on hazard quotients. Many uncertainties come into the question when trying to calculate the hazard quotients. Theoretically, the exposure is calculated from measured values in the different environmental compartments. However, in most of the cases, this data is unavailable or insufficient due to the complexities inherent to environments. Due to this fact, models have become very useful tools in predicting concentrations of certain contaminants in specific compartments. In many risk assessments, the actual concentrations in the environment are not measurable so risk assessors must use models to predict what these concentrations will likely be.

In China, there is very little analytical information available concerning the occurrence and fate of risk assessment during reuse applications. The paper is cooperation in Beijing in Beiyun river. For the recycled water for landscape water is evaluated. Establish the recycled water utilization assessment parameter. The purpose of this paper is to provide quantitative basis of risk assessments.

\section{Study Area Description}

The study was carried out along the Beiyun River, located in the Haihe Basin, one of main basins present in China. With an area of about $4348 \mathrm{~km}^{2}$, the basin is situated in Beijing, with mean precipitation of $532.5 \mathrm{~mm}(1980-2000)$ a year. The precipitation is concentrated in certain months of the year causing large flow fluctuations of the watercourses and therefore, leading to important differences in the dilution of the compounds present in waste water discharges. Fig. 1 shows the location of the Beiyun River Basin within Beijing. Beiyun river has completed some city sewage treatment plant, with design processing ability of 254 million ton per day, actual treating capacity is 214.4 million ton per day. 


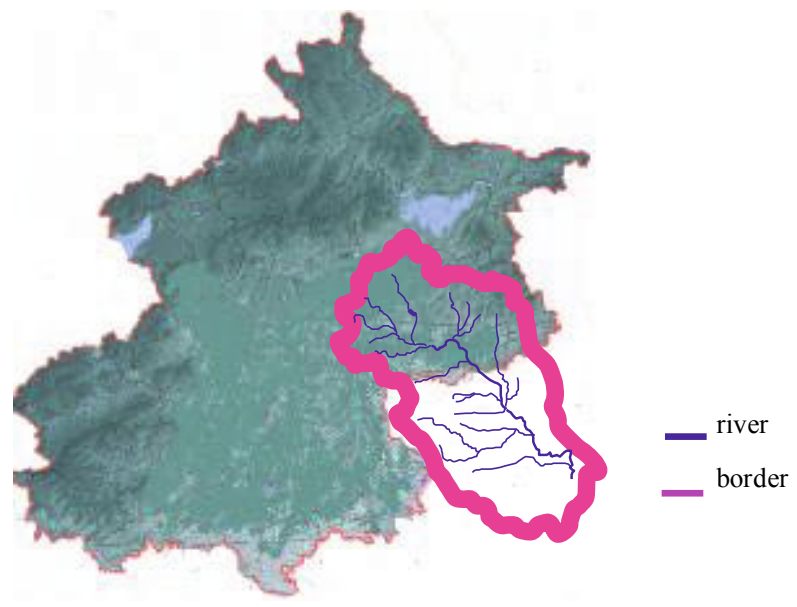

Fig. 1. Beiyun River inside Beijing

\section{Results and Discussion}

\subsection{Distribution of Reclaimed Water}

Pollution intensity calculation of treatment facilities Pollution discharge =water dischargex Pollutant emission concentration. All data are from the pollution sources census data. According to the discharge of reclaimed water distribution layout of different districts is finished based on GIS.
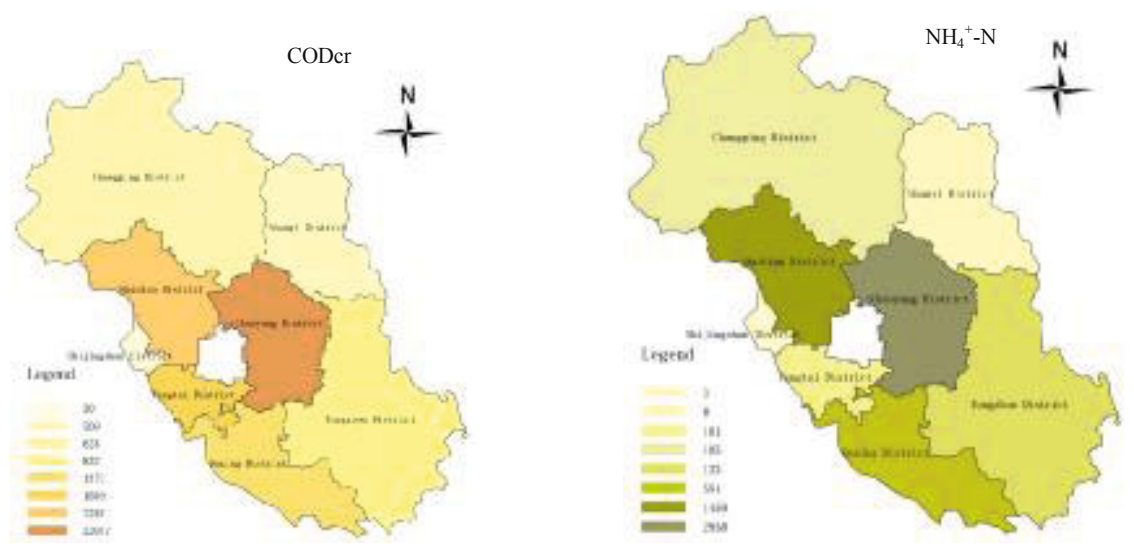

Fig. 2. $\mathrm{COD}_{\mathrm{cr}}$ and $\mathrm{NH}_{4}{ }^{+}-\mathrm{N}$ pollution load in different districts based on GIS (unit : t/a) . Data shows $\mathrm{COD}_{\mathrm{cr}}$ discharge of treatment facilities is 3.44 thousand t/a, $\mathrm{NH}_{4}{ }^{+}-\mathrm{N}$ discharge of treatment facilities is 0.53 thousand $\mathrm{t} / \mathrm{a}$. According to the administrative division, The area of biggest emissions is Chaoyang district, Percentage of $64.1 \%$. The second discharge area is Haidin district, Percentage of $21.2 \%$. 
Table 1. Comparative analysis between water quality of reclaimed water and surface water environment quality standards (mg/l)

\begin{tabular}{|c|c|c|c|c|c|c|}
\hline $\mathrm{NO}$ & Analyze item & III & IV & V & primary (A) & Remarks \\
\hline 1 & Temperature $\left({ }^{\circ} \mathrm{C}\right)$ & _ & - & - & - & - \\
\hline 2 & $\mathrm{PH}$ & $6-9$ & $6-9$ & $6-9$ & $6-9$ & _- \\
\hline 3 & $\mathrm{DO} \geq$ & 5 & 3 & 2 & - & - \\
\hline 4 & $\mathrm{COD}_{\mathrm{Mn}} \leq$ & 6 & 10 & 15 & - & - \\
\hline 5 & $\mathrm{COD}_{\mathrm{Cr}} \leq$ & 20 & 30 & 40 & 50 & over \\
\hline 6 & $\mathrm{BOD}_{5} \leq$ & 4 & 6 & 10 & 10 & over \\
\hline 7 & $\mathrm{NH}_{4}-\mathrm{N} \leq$ & 1.0 & 1.5 & 2.0 & $5(8)$ & over \\
\hline 8 & $\mathrm{TP} \leq$ & $\begin{array}{c}0.2 \\
(0.05)\end{array}$ & $\begin{array}{c}0.3 \\
(0.1)\end{array}$ & $\begin{array}{c}0.4 \\
(0.2)\end{array}$ & $0.5-1$ & over \\
\hline 9 & $\mathrm{TN} \leq$ & 1.0 & 1.5 & 2.0 & 15 & over \\
\hline 10 & $\mathrm{Cu} \leq$ & 1.0 & 1.0 & 1.0 & 0.5 & ok \\
\hline 11 & $\mathrm{Zn} \leq$ & 1.0 & 2.0 & 2.0 & 1.0 & ok \\
\hline 12 & fluoride $\leq$ & 1.0 & 1.5 & 1.5 & & - \\
\hline 13 & $\mathrm{Se} \leq$ & 0.01 & 0.02 & 0.02 & 0.1 & over \\
\hline 14 & $\mathrm{As} \leq$ & 0.05 & 0.1 & 0.1 & 0.1 & ok \\
\hline 15 & $\mathrm{Hg} \leq$ & 0.0001 & 0.001 & 0.001 & 0.001 & ok \\
\hline 16 & $\mathrm{Cd} \leq$ & 0.005 & 0.005 & 0.01 & 0.01 & ok \\
\hline 17 & $\mathrm{Cr}($ six valence $) \leq$ & 0.05 & 0.05 & 0.1 & 0.05 & ok \\
\hline 18 & $\mathrm{~Pb} \leq$ & 0.05 & 0.05 & 0.1 & 0.1 & ok \\
\hline 19 & cyanide $\leq$ & 0.2 & 0.2 & 0.2 & 0.5 & ok \\
\hline 20 & Volatilization phenol $\leq$ & 0.005 & 0.01 & 0.1 & 0.5 & over \\
\hline 21 & Oil $\leq$ & 0.05 & 0.5 & 1.0 & 1 & over \\
\hline 22 & $\mathrm{LAS} \leq$ & 0.2 & 0.3 & 0.3 & 0.5 & ok \\
\hline 23 & sulphide $\leq$ & 0.2 & 0.5 & 1.0 & 1.0 & ok \\
\hline 24 & coliform $(\mathrm{a} / \mathrm{L}) \leq$ & 10000 & 20000 & 40000 & 1000 & ok \\
\hline
\end{tabular}




\subsection{Assessment of Reclaimed Water}

In China, water quality standard in the reclaimed water use are different due to reclaimed ways. For example: reclaimed in agriculture perform "Standards for irrigation water puality" (GB 5084-2005); using water in fisheries perform "Water quality standard for fisheries" (GB 11607-89); using in scenic environment, and include water function range, perform "Environmental quality standards for surface water" (GB 3838-2002), and over water function range, perform reuse of " urban recycling water-Water quality standard for scenic environment use" (GB/T 189212002); using in industry cooling perform "Code for desing of wastewater reclamation and reuse" (GB/T 50335-2002); using in city cooling perform reuse of recycling water for urban water quality standard for urban miscellaneous water consumption $)$ (GB/T 18920-2002).

This paper process water quality assessment depend on primary(A) of discharge in sewage plant. Because Beiyun river includes in water function range, perform "Environmental quality standards for surface water" (GB 3838-2002) .

Comparison between water quality with the primary discharge standard and "Environmental quality standards for surface water" (GB 3838-2002): poor V species, main overpollutant are $\mathrm{COD}_{\mathrm{Cr}} 、 \mathrm{NH}_{4}{ }^{+}-\mathrm{N}$ and TP.

\section{Conclusions}

Discharge of treatment facilities is bigger in Beiyun river. The area of biggest emissions is Tongzhou district, Percentage of $64.1 \%$. The second discharge area is Changping district, Percentage of $21.2 \%$. So it is necessary to improve sewage plant effluent standards to improve the quality of water environment of Beijing rivers.

Overall, the irrigation water can be directly used in the secondary water level of treatment facilities. The use of recycled water for the irrigation of crops has benefits in using a resource that would otherwise be discarded and wasted. Using recycled water also reduces the pressures on the environment by reducing the use of environmental waters. Reclaimed water must pass through different degree of deep processing and the corresponding standards for direct using, and the depth of water storage with reclaimed water to avoid entering drinking water range. Ongoing research will improve the use of reclaimed water as well as increasing public confidence.

\section{Acknowledgments}

The authors are grateful for support from the Restorative Project of Urban Water Environment (2008ZX07209-002 and 2008ZX07209-004) and Community Foundation of Ministry of Water Resources (200901083). 


\section{References}

1. Shereif, M.M., Easa, M.E.S., El-Samra, M.I., Mancy, K.H.: A demonstration of wastewater treatment forreuse applications in fish production and irrigation in Suez. Egypt. Water Sci. Technol. 32, 137-144 (1995)

2. Asano, T., Maeda, M., Takaki, M.: Wastewater reclamation and reuse in Japan: overview and implementation examples. Water Sci. Technol. 34, 219-226 (1996)

3. Haarhoff, J., Van der Merwe, B.: Twenty-five years of wastewater reclamation in Windhoek. Nambia. Water Sci. Technol. 33, 25-35 (1996)

4. Dillon, P.J., Pavelic, P., Gerges, N.Z., Armstrong, D., Emmett, A.J.: Artificial recharge of groundwater. In: Proceeding of the Second International Symposium Artificial Recharge of Ground Water, pp. 426-435 (1994)

5. Anderson, J.M.: Current water recycling initiatives in Australia: scenarios for the $21 \mathrm{st}$ century. Water Sci.Technol. 33, 37-43 (1996)

6. Guillaume, P., Xanthoulis, D.: Irrigation of vegetable crops as a means of recycling wastewater: applied to Hesbaye Frost. Water Sci. Technol. 33, 317-326 (1996)

7. Meli, S., Maurizio, M., Belligno, A., Bufo, S.A., Mazzatura, A., Scopa, A.: Influence of irrigation with lagooned urban wastewater on chemical and microbial soil parameters in a citrus orchard under Mediterranean condition. Sci. Total Environ. 285, 69-77 (2002)

8. Ramirez-Fuentes, E., Lucho-Constantino, C., Escamilla-Silva, E., Dendooven, L.: Characteristics, and carbon and nitrogen dynamics in soil irrigated with wastewater for different lengths of time. Bioresour. Technol. 85, 179-187 (2002) 